\title{
NILAI TROMBOSIT PADA PASIEN PENYAKIT GINJAL KRONIK YANG MENJALANI HEMODIALISIS DI UNIT HEMODIALISIS BAGIAN/SMF ILMU PENYAKIT DALAM FK UNSRAT BLU RSUP PROF. DR. R. D. KANDOU MANADO
}

\author{
${ }^{1} J e s i n t a$ Kaparang \\ ${ }^{2}$ Emma Sy Moeis \\ ${ }^{2}$ Linda Rotty \\ ${ }^{1}$ Kandidat Skripsi Fakultas Kedokteran Unsrat Manado \\ ${ }^{2}$ Bagian Ilmu Penyakit Dalam Fakultas Kedokteran Unsrat Manado \\ Email: jesinta_kaparang@ymail.com
}

\begin{abstract}
Bacground: Stadium V Chronic Kidney Disease is less than $15 \mathrm{ml} / \mathrm{mnt}$ GFR, there is an accumulation of toxin uremia in blood that could harm the survival of patient, it is required a substitute therapy for the kidney,which is called hemodialysis. Hemodialisis needs anticoagulation, so blood clotting in circuit extracorporeal does not occur. In its development, have been tried several kinds of anticoagulation technique and anticoagulant which is made based on the state of the patient such as heparin, but in its using it can cause side effects. The work of heparin as anticoagulant dependents on anti thrombin (AT-III) that is an inhibitor of various factor of clotting. Heparin can cause changing of homeostasis because of its effect to the function of thrombosis ( thrombosis aggregation ) even to reduce the number of thrombosis ( Heparin Induced Thrombocytopenia ). Purpose: To know and to study about the value of thrombosis in CKD patient who endure hemodialysis in unit hemodialisis Department of Internal Medicine BLU RSUP Prof. Dr.R.D. Kandou Manado.Method : Descriptive retrospective, using secondary data medic record in unit hemodyalisis Department of Internal Medicine BLU RSUP Prof. DR .R. D. Kandou Manado. Result: The thrombocytopenia patient increased on HD $>96 \mathrm{X}$, most of them are men in range $51-60$ years old. Conclusion: CKD patient who endure hemodyalisis generally have normal thrombosis value, number of thrombocytopenia case is $25,45 \%$ and number of most occurrence is commonly to men
\end{abstract}

Keywords: chronic kidney disease, hemodialysis, thrombocytopenia.

\begin{abstract}
Abstrak: Latar Belakang: Penyakit ginjal kronik stadium V yaitu LFG kurang dari $15 \mathrm{ml} / \mathrm{mnt}$ terdapat akumulasi toksin uremia dalam darah yang dapat membahayakan kelangsungan hidup pasien, sehinga di perlukan terapi penganti ginjal, terapi pengganti ginjal tersebut berupa hemodialisis. Pada hemodialisis diperlukan antikoagulasi supaya tidak terjadi pembekuan darah didalam sirkuit ekstrakorporeal. Dalam perkembangannya telah dicoba beberapa macam teknik antikoagulasi dan antikoagulan yang dibuat berdasarkan keadaan pasien,seperti heparin tetapi dalam pengunaanya heparin dapat memberikan efek samping Kerja heparin sebagai antikoagulasi bergantung pada antitrombin (AT-III) yaitu suatu inhibitor dari berbagai faktor pembekuan. Heparin menyebabkan perubahan hemostasis karena efeknya terhadap fungsi trombosit (agregasi trombosit) bahkan menurunkan jumlah trombosit (Heparin Induced Thrombocytopenia). Tujuan:Mengetahui dan mempelajari nilai trombosit pada pasien PGK yang menjalani hemodialisis di unit hemodialisis bagian/SMF Ilmu Penyakit Dalam BLU RSUP. Prof.Dr.R.D.Kandou manado. Metode Penelitian: Deskriptif retospektif dengan mengunakan data sekunder rekam medik di unit Hemodialisis Bagian/SMF Ilmu Penyakit dalam BLU RSUP Prof.DR. R. D. Kandou Manado. Hasil: Pasien yang mengalami trombositopeni mengalami peningkatan pada Hemodialisis lebih dari 96 kali, terbanyak
\end{abstract}


berjenis kelamin laki - laki pada kelompok umur 51 - 60 tahun. Simpulan: Pasien PGK yang menjalani hemodialisis pada umumnya mempunyai nilai trombosit normal, jumlah kasus trombositopeni 25,45\%, dan angka kejadian terbanyak umumnya pada laki-laki.

Kata Kunci: Penyakit ginjal kronik, hemodialisis, trombositopeni

Penyakit ginjal kronik ( PGK ) adalah suatu proses patofisiologis dengan etiologi yang beragam, mengakibatkan penurunan fungsi ginjal yang progresif, dan pada umumnya berakhir dengan gagal ginjal. ${ }^{1}$

PGK sering ditemukan, menurut data dari The United States Renal Data System (USRDS) tahun 2009 prevalensinya sekitar 10-13\%. Di Amerika Serikat jumlahnya mencapai 25 juta orang, di Indonesia diperkirakan 12,5\% atau sekitar 18 juta orang. ${ }^{2}$

Laju Filtrasi Glomerulus ( LFG ) dianggap sebagai ukuran terbaik dari ginjal, LFG normal keseluruhan fungsi bervariasi sesuai dengan usia pasien, jenis kelamin, dan ukuran tubuh. Pada orang dewasa muda, LFG normal adalah kurang lebih $120-130 \mathrm{ml} / \mathrm{menit} / 1,73 \mathrm{~m}^{2}$ dan dengan menurun umur 14-17 Tingkat LFG di bawah $60 \mathrm{~mL} /$ menit $/ 1,73 \mathrm{~m}^{2}$ merupakan kehilangan satu setengah atau lebih dari tingkat dewasa normal fungsi ginjal. ${ }^{3}$

PGK didefinisikan denggan LFG di bawah $15 \mathrm{~mL} / \mathrm{menit} / 1,73 \mathrm{~m}^{2}$, biasanya disertai dengan tanda-tanda dan gejala uremia. Di Amerika Serikat, sekitar $98 \%$ pasien dialisis dimulai ketika mereka LFG turun di bawah $15 \mathrm{ml} /$ menit $/ 1,73 \mathrm{~m}^{2}{ }^{3}$.

Tahapan PGK dapat dibagi menurut beberapa cara antara lain dengan memperhatikan faal ginjal yang masih tersisa. Bila faal ginjal yang masih tersisa sudah minimal sehingga pengobatan-pengobatan yang konserfatif yang berupa diet, pembatasan minum, obat-obatan, dan lain-lain tidak memberi pertolongan yang diharapkan lagi, keadaan tersebut diberi nama penyakit ginjal kronik. Pada stadium ini terdapat akumulasi toksin uremia dalam darah yang dapat membahayakan kelangsungan hidup pasien. Pada umumnya faal ginjal yang masih tersisa, yang diukur dengan klirens kreatinin (KKr). Tidak lebih dari $15 \mathrm{ml} / \mathrm{menit} / 1,73 \mathrm{~m}^{2}$. Pasien PGK stadium V, apapun etiologinya, me-merlukan pengobatan khusus pengobatan atau terapi penganti ginjal (TPG). ${ }^{1}$

Terapi penganti ginjal dilakukan pada penyakit ginjal kronik stadium $\mathrm{V}$, yaitu pada LFG kurang dari $15 \mathrm{ml} / \mathrm{mnt} / 1,73 \mathrm{~m}^{2}$. Terapi pengganti ginjal tersebut berupa hemodialisis, peritoneal dialysis atau transplantasi ginjal. ${ }^{1}$
Selama berlangsungnya hemodialisis diperlukan antikoagulasi supaya tidak terjadi pembekuan darah didalam sirkuit ekstra korporeal. Dalam perkembangannya telah dicoba beberapa macam teknik antikoagulasi yang dibuat berdasarkan keadaan pasien, juga beberapa macam antikoagulan selain heparin pernah dicoba dan beberapa masih diupayakan. Semua ini untuk mendapatkan antikoagulan yang dalam pemakaian jangka panjang tidak memberikan efek samping. Akan tetapi dilihat dari kesederhanaan pemberiannya, maka heparin berat molekul besar (Unfractioned Heparine) masih merupakan standar anti koagulan yang digunakan selama prosedur hemodialisis. $^{2}$

Pada proses dialisis terjadi aliran darah di luar tubuh. Pada keadaan ini akan terjadi aktivasi sistem koagulasi darah dengan akibat timbulnya bekuan darah. Karena itu pada dialisis diperlukan pemberian heparin selama dialisis berlangsung. Ada tiga teknik pemberian heparin yaitu teknik heparin rutin, heparin minimal, dan bebas heparin. Pada teknik heparin rutin, teknik yang paling sering digunakan sehari - hari, heparin diberikan dengan cara bolus diikuti dengan continuus infusion. ${ }^{1}$

\section{METODE PENELITIAN}

Penelitian ini dilakukan secara deskriptif retrospektif dengan mengunakan data sekunder rekam medik di Unit Hemodialisis Bagian/SMF Ilmu Penyakit dalam BLU RSUP Prof.Dr.R.D. Kandou Manado yang bertujuan untuk mengetahui dan mempelajari nilai trombosit pada pasien PGK yang menjalani hemodialisis di unit hemodialisis bagian/SMF Ilmu Penyakit Dalam BLU RSU. Prof.Dr.R.D.Kandou manado. Waktu penelitian dilakukan pada bulan November 2011 - Januari 2012. Populasi penelitian ini ialah pasien PGK yang telah menjalani Hemodialisis (HD) lebih dari 96 kali di unit Hemodialisis Bagian/SMF Ilmu Penyakit dalam BLU RSUP Prof. DR. R. D. Kandou Manado. Subjek Penelitian ialah semua pasien PGK yang menjalani HD lebih dari 96 kali di unit hemodialisis Bagian/SMF 
Ilmu Penyakit Dalam BLU RSUP. Prof. Dr. R. D. Kandou Manado. Variabel penelitian yang di teliti meliputi : Umur, Jenis Kelamin, Cara pemberian heparin, jenis heparin, frekuensi HD dan pemeriksaan laboratorium yaitu trombosit pada awal HD, HD ke 24, HD ke 48 dan HD ke lebih dari 96 kali.

Pengumpulan data dilakukan dengan melihat catatan rekam medis pasien PGK yang telah menjalani HD lebih dari 96 kali di unit hemodialisis Bagian Ilmu Penyakit dalam BLU RSU Prof.Dr.R.D.Kandou Manado. Pengelolahan data dilakukan secara manual dan data yang ada dihitung dalam table frekuensi dan penyajiannya di uraikan dalam kalimat dan dalam bentuk tabel distribusi.Total data rekam medis pasien yang diperoleh berdasarkan penelitian yaitu 55 data pasien yang menjalani Hemodialisis lebi dari 96 kali dengan diagnosis PGK, tetapi data pemeriksaan laboratorium yang diperoleh khususnya nilai trombosit hanya sebanyak 48 pasien. Setelah dilakukan pengambilan data nilai trombosit pada pasien sesuai dengan lamanya pasien menjalani hemodialisis nilai trombosit kurang dari $150.000 / \mu \mathrm{L}$ pada awal HD dan pada HD ke24 kali tidak ditemukan, HD ke-48 kali sebanyak dua pasien $(4,17 \%)$ dan pada HD lebih dari 96 kali sebanyak 13 pasien $(27,08$ $\%)$, nilai trombosit $150.000-450.000 / \mu \mathrm{L}$ pada awal HD empat pasien (8,33 \%), HD ke-24 kali sebanyak dua pasien (4,17\%), HD ke-48 kali sebanyak dua pasien $(4,17 \%)$, HD lebih dari 96 kali sebanyak 24 pasien (50 \%) dan trombosit $>450.000 / \mu \mathrm{L}$ sebanyak satu pasien $(2,08 \%)$ pada HD lebih dari 96 kali. Ditribusi terbesar ada pada nilai trombosit normal $150.000-450.000 / \mu \mathrm{L}$ pada awal HD sebanyak empat pasien $8,33 \%$.

Berdasarkan kelompok umur dan jenis kelamin pasien PGK yang menjalani HD dengan trombositopenia berdasarkan frekuensi HD memiliki distribusi pada kelompok umur 51- 60 tahun pada awal HD, HD ke-24, dan HD ke-48 tidak ditemukan dan pada HD lebih dari 96 kali sebanyak empat pasien $26,67 \%$ berjenis kelamin laki-laki, umur 61-70 tahun pada awal HD, dan HD ke-24 tidak ditemukan, HD ke 48 satu pasien perempuan $6,67 \%$ dan pada HD lebih dari 96 kali sebanyak tiga pasien laki laki $26,67 \%$, kelompok umur 41-50 pada awal HD dan HD ke-24 tidak ditemukan, HD ke-48 satu pasien perempuan $6,67 \%$ dan HD lebih dari 96 kali.

Tabel 1. Distribusi Nilai trombosit pada pasien PGK.

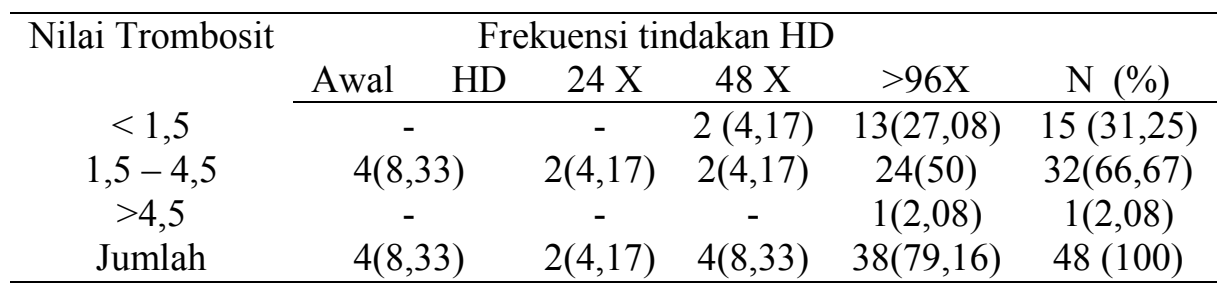

Tabel 2. Distribusi pasien PGK yang menjalani HD dengan trombositopenia berdasarkan umur, jenis kelamin dan frekuensi HD.

\begin{tabular}{|c|c|c|c|c|c|c|c|c|c|}
\hline \multicolumn{10}{|c|}{ Frekuensi HD } \\
\hline \multirow{2}{*}{$\begin{array}{l}\text { Umur } \\
\text { (tahun) }\end{array}$} & \multicolumn{2}{|c|}{ Awal HD } & \multicolumn{2}{|c|}{$24 X$} & \multicolumn{2}{|c|}{$48 X$} & \multicolumn{2}{|c|}{$>96 \mathrm{X}$} & \multirow[b]{2}{*}{$\begin{array}{l}\mathrm{N} \\
(\%)\end{array}$} \\
\hline & $\begin{array}{c}\mathrm{L} \\
\mathrm{N}(\%)\end{array}$ & $\begin{array}{c}\mathrm{P} \\
\mathrm{N}(\%)\end{array}$ & $\begin{array}{c}\mathrm{L} \\
\mathrm{N}(\%)\end{array}$ & $\begin{array}{c}\mathrm{P} \\
\mathrm{N}(\%)\end{array}$ & $\begin{array}{c}\mathrm{L} \\
\mathrm{N}(\%)\end{array}$ & $\begin{array}{c}\mathrm{P} \\
\mathrm{N}(\%)\end{array}$ & $\begin{array}{c}\mathrm{L} \\
\mathrm{N}(\%)\end{array}$ & $\begin{array}{c}\mathrm{P} \\
\mathrm{N}(\%)\end{array}$ & \\
\hline $20-30$ & - & - & - & - & - & 0 & $2(13,33)$ & 0 & $2(13,33)$ \\
\hline $31-40$ & - & - & - & - & - & 0 & $1(6,67)$ & $1(6,67)$ & $2(13,33)$ \\
\hline $41-50$ & - & - & - & - & - & $1(6,67)$ & $2(13,33)$ & 0 & $3(20)$ \\
\hline $51-60$ & - & - & - & - & - & 0 & $4(26,67)$ & 0 & $4(26,67)$ \\
\hline $61-70$ & - & - & - & - & - & $1(6,67)$ & $3(20)$ & 0 & $4(26,67)$ \\
\hline Jumlah & & - & - & - & - & $2(13,34)$ & $12(80)$ & $1(6,67)$ & $15(100)$ \\
\hline
\end{tabular}


dua pasien laki-laki 13,33\%, kelompok umur 31-40 pada awal HD sampai HD ke-48 tidak ditemukan dan pada HD lebih dari 96 kali sebanyak satu pasien laki-laki $6,67 \%$ dan satu pasien perempuan $6,67 \%$, kelompok umur 21 30 pada awal HD sampai HD ke-48 tidak ditemukan dan pada HD lebih dari 96 kali sebanyak dua pasien laki-laki 13,33\%.

Berdasarkan frekuensi lamanya pasien menjalani HD dengan trombositopenia, didapatkan pasien yang menjalani HD lebih dari satu tahun (lebih dari 96 kali) sebanyak tujuh pasien $46,67 \%$, lebih dari dua tahun sebanyak dua pasien $(13,33 \%)$ dan lebih dari tiga tahun sebanyak enam pasien $40 \%$.

Tabel 3. Distribusi pasien PGK yang menjalani HD dengan trombositopenia berdasarkan frekuensi lamanya pasien menjalani HD

\begin{tabular}{cc}
\hline $\begin{array}{c}\text { Frekuensi HD } \\
(\text { tahun })\end{array}$ & $\mathrm{N}(\%)$ \\
\hline$>1$ tahun $(>96 \mathrm{X})$ & $7(46,67)$ \\
$>2$ tahun $(>192 \mathrm{X})$ & $2(13,33)$ \\
$>3$ tahun $(>288 \mathrm{X})$ & $6(40)$ \\
Jumlah & $15(100)$ \\
\hline
\end{tabular}

Berdasarkan cara pemberian heparin yang diberikan terhadap pasien didapatkan kontinyu dua pasien $(14,28 \%)$ dan intermiten 13 pasien $(85,71 \%)$

Tabel 4. Distribusi pasien PGK yang menjalani HD dengan trombositopenia berdasrkan cara pemberian heparin yang diberikan

\begin{tabular}{cc}
\hline Cara pemberian Heparin & $\mathrm{N}(\%)$ \\
\hline Kontinyu & $2(14,28)$ \\
Intermiten & $13(85,71)$ \\
Jumlah & $15(100)$ \\
\hline
\end{tabular}

Berdasarkan jenis heparin yang diberikan di dapatkan heparin tak terpecah 15 pasien (100 \%) dan heparin berat molekul rendah tidak ada pasien.

Tabel 5. Distribusi pasien PGK yang menjalani HD dengan thrombositopenia berdasarkan jenis heparin.

\begin{tabular}{cc}
\hline Jenis Heparin & $\mathrm{N}(\%)$ \\
\hline Heparin tak terpecah (UFH) & $15(100)$ \\
Heparin berat molekul & - \\
rendah (LMWH) & \\
Jumlah & $15(100)$ \\
\hline
\end{tabular}

\section{BAHASAN}

Selama penelitian yang dilakukan pada bulan November 2011-Januari 2012 di unit hemodialisis di bagian SMF Ilmu Penyakit Dalam BLU RSU Prof. Dr. R. D. Kandou manado didapatkan 55 pasien yang menjalani HD lebih dari 96 kali dengan diagnosis PGK, tetapi data pemeriksaan trombosit yang di peroleh hanya 48 pasien $(87,47 \%)$, jadi ada tujuh pasien $(12,27 \%)$ yang tidak diperoleh data pemeriksaan trombosit, dan jumlah trombosit normal didapatkan pada 32 pasien $(66,67 \%)$, dan hanya 15 pasien $(31,25 \%)$ yang mengalami trombositopenia.

Setelah dilakukan pengambilan data nilai trombosit pada pasien sesuai dengan lamanya pasien menjalani hemodialisis ditribusi terbesar ada pada nilai trombosit normal 150.000$450.000 / \mu \mathrm{L}$ pada awal HD sebanyak empat pasien $(8,33 \%)$, HD ke-24 sebanyak dua pasien $(4,17 \%)$, HD ke-48 sebanyak dua pasien $(4,17 \%)$ HD lebih dari 96 kali sebanyak 24 pasien $(50 \%)$ diikuti penurunan nilai trombosit $<150.000 / \mu \mathrm{L}$ pada awal HD dan pada HD ke24 tidak ditemukan, HD ke-48 sebanyak dua pasien $(4,17 \%)$ dan pada HD lebih dari 96 kali sebanyak 13 pasien $(27,08 \%)$, sedangkan trombosit $>450.000 / \mu \mathrm{L}$ satu pasien $(2,08 \%)$ pada HD lebih dari 96 kali. Maksud pemeriksaan menurut frekuensi HD yaitu pada awal HD, HD ke-24, HD ke-48 dan HD lebih dari 96 kali adalah untuk mengetahui perubahan jumlah trombosit akibat pemberian heparin selama HD. Dengan data yang ada umumnya nilai trombosit normal sesuai dengan kepustakaan yang mengatakan bahwa bila dilakukan pengontrolan yang ketat terhadap pemberian heparin tidak akan memberikan efek samping yang banyak. Sedangkan dalam kasus ini pasien yang mengalami trombositopenia menunjukan adanya efek samping heparin. Dalam data ini pasien yang mengalami trombositopeni berdasarkan lamanya HD yaitu pada HD ke-48 dan lebih dari 96 kali, hal ini sesuai dengan kepustakaan yang mengatakan bahwa semakin lama terpapar dengan heparin atau pengunaan heparin yang berulang akan memberikan efek samping trombositopeni. ${ }^{4,5}$

Distribusi pasien PGK yang menjalani HD dengan trombositopenia berdasarkan kelompok umur dan frekuensi HD memiliki distribusi terbesar pada kelompok umur 51-60 tahun pada awal HD, HD ke-24, dan HD ke-48 tidak ditemukan dan pada HD lebih dari 96 kali sebanyak empat pasien $(26,67 \%)$ berjenis 
kelamin laki-laki, umur 61-70 tahun pada awal HD, dan HD ke-24 tidak ditemukan, HD ke-48 sebanyak satu pasien perempuan $(6,67 \%)$ dan pada HD lebih dari 96 kali sebanyak tiga pasien laki-laki (26,67\%), kelompok umur 41-50 pada awal HD dan HD ke-24 tidak ditemukan, HD ke-48 satu pasien perempuan $(6,67 \%)$ dan HD lebih dari 96 kali sebanyak dua pasien laki-laki 13,33\%, kelompok umur 31-40 pada awal HD sampai HD ke-48 tidak ditemukan dan pada HD lebih dari 96 kali sebanyak satu pasien laki-laki $(6,67 \%)$ dan satu pasien perempuan (6,67\%), kelompok umur 21-30 pada awal HD sampai HD ke-48 tidak ditemukan dan pada HD ebih dari 96 kali sebanyak dua pasien lakilaki $(13,33 \%)$. Data ini sesuai dengan kepustakaan bahwa jumlah pasien yang menjalani HD terbanyak adalah usia lanjut karena faktor resiko PGK adalah usia lanjut, serta fungsi trombosit berhubungan dengan perbaikan kerusakan dinding pembuluh darah yang dapat mempengaruhi hemostasis tubuh dan pada usia lanjut keadaan itu menurun. ${ }^{3}$

Distibusi pasien PGK berdasarkan jenis kelamin dengan trombositopenia didapatkan pada pria lebih banyak dari pada wanita yaitu pria sebanyak 12 pasien $(80 \%)$, sedangkan wanita sebanyak tiga pasien $(20 \%)$. Hal ini sesesuai dengan hasil penelitian bahwa jumlah pasien yang menjalani HD lebih banyak adalah pria dari wanita, tetapi tidak sesuai dengan penelitian yang mengatakan bahwa heparin induced thrombocytopenia (HIT) lebih banyak terjadi pada wanita dari pada pria. ${ }^{6}$

Berdasarkan frekuensi lamanya pasien menjalani HD dengan trombositopenia, didapatkan pasien yang menjalani HD lebih dari satu tahun (lebih dari 96 kali) tujuh pasien $(50 \%)$, lebih dari dua tahun satu pasien $(7,14 \%)$ dan lebih dari tiga tahun enam pasien $(42,86 \%)$.

Distibusi pasien PGK yang menjalani HD dengan trombositopenia berdasarkan jenis heparin yang diberikan terhadap pasien kontinyu dua pasien $(14,28 \%)$ dan intermiten 12 pasien $(85,71 \%)$.

Distribusi pasien PGK dengan trombositopeni berdasarkan jenis heparin yang diberikan di dapatkan heparin tak terpecah 15 pasien $(100 \%)$ dan heparin berat molekul rendah tidak ada pasien. Hal ini seuai dengan penelitian yang mengatakan HIT terjadi pada sekitar 1\%-5\% dari pasien diberikan heparin tak terpecah dan kurang dari $1 \%$ pasien yang diberikan berat rendah molekul heparin. ${ }^{6}$

\section{SIMPULAN DAN SARAN}

Nilai trombosit pada pasien PGK yang menjalani HD lebih dari 96 kali umumnya normal yaitu 32 pasien (66,67\%). Jumlah kasus trombositopenia pada pasien PGK yang menjalani HD sebanyak 15 pasien.

Pasien PGK yang menjalani HD dan mengalami thrombositopenia terbanyak pada umur 51-60 dan 61-70 yaitu masingmasing kelompok umur empat pasien (26,67\%). Angka kejadian terbanyak pada pria diban-dingkan wanita.

Frekuensi lamanya pasien menjalani HD terbanyak lebih dari dari tahun (lebih dari 96 kali) yaitu sebanyak enam pasien $(46,15 \%)$.

Jenis heparin yang diberikan umumnya heparin tak terpecah. Dari hasil penelitian ini disarankan bagi pihak pemberi pelayanan di rumah sakit (dokter dan tenaga medis) agar kiranya dapat melengkapi data-data pasien pada rekam medik agar dalam penelitian dapat diperoleh data yang akurat dan dalam pengunaan heparin kiranya dapat dilakukan pengontrolan yang ketat dari petugas medis sehingga dapat mengangani dan mencegah lebih cepat terjadinya thrombositopenia dan efek samping lainya dari heparin pada pasien PGK yang menjalani HD, dan pemilihan antikoagulasi lain seperti LMWH dapat dipertimbangkan untuk mencegah terjadinya Heparin Induced Thrombocytopenia.

\section{DAFTAR PUSTAKA}

1. Suwitra Ketut. Gagal Ginjal Kronik. Dalam: Buku Ajar Ilmu Penyakit Dalam Jilid II. (Edisi Kelima) Jakarta. Departemen Ilmu Penyakit Dalam, 2009; h.1035-40.

2. Islamudin. Antikoagulan pada hemodialisis [homepage on the internet]. c2011 [updated 2011 Jan 27; cited 2011 Nov 11]. Available from: http://antikoagulan-pada hemodialisis « Internal Medicine Blog.htm

3. Johnson CA, Levey SA, Coresh J. Clinical Practice Guidelines for Chronic Kidney Disease in Adults: Part I. Definition, Disease Stages, Evaluation, Treatment, and Risk Factors Am Fam Physician. 2004 Sep 1; 70(5):869-876.

4. Hoffbrand AV, Pettit JE, Moss PAH. Kapita Selekta Hematologi (Edisi Keempat). Jakarta: EGC, 2005; h. 265-267. 
5. Dewoto RH. Antikoagulan. Farmakologi dan Terapi (Edisi Kelima). Jakarta: Departemen Farmakologi dan Teraupetik, 2007; h.806-10.
6. Levy JH, Tanaka KA, Hursting MJ. DABCC: Reducing Thrombotic Complications in the Perioperative Setting: An Update on Heparin-Induced Thrombocytopenia. Anesth. Analg. 2007;105:570-582. 